Research paper

\title{
Analysis of lock-exchange gravity currents over smooth and rough beds
}

\author{
HELENA I.S. NOGUEIRA, PhD Student, Department of Civil Engineering \& IMAR-CMA, University of Coimbra, Rua Luís Reis \\ Santos - Pólo II, 3030-788 Coimbra, Portugal. \\ Email: hnogueira@dec.uc.pt,lenanogue@gmail.com (author for correspondence)
}

CLAUDIA ADDUCE (IAHR MEMBER), Assistant Professor, Department of Civil Engineering, University of Rome, "Roma Tre”, Via Vito Volterra, 62, 00146 Rome, Italy.

Email: adduce@uniroma3.it

ELSA ALVES, Research Officer, Department of Hydraulics and Environment, National Laboratory of Civil Engineering, Av. do Brasil, 101, 1700-066 Lisbon, Portugal.

Email: ealves@lnec.pt

MÁRIO J. FRANCA (IAHR MEMBER), Assistant Professor, Department of Civil Engineering \& IMAR-CMA, New University of Lisbon, Quinta da Torre, 2829-516 Caparica, Portugal.

Email:mfranca@fct.unl.pt

\begin{abstract}
Gravity currents produced by full-depth lock-release of saline water into a fresh water tank are studied focusing on the influence of the initial density of the saline mixture in the lock and the bed roughness on gravity current kinematics. Temporal evolution of the current front position and front velocity are analysed and related to different phases of the current. Time-space evolution of current depth-averaged density and current height are assessed as well. Roughness of the channel bed plays an important role in the current kinematics, particularly in decreasing the front velocity due to extra drag at the bed. The analysis of Froude numbers, estimated with the initial and local reduced gravity and established with different length scales of the current, allow for the definition of the important variables and current dynamics of each phase of the current development.
\end{abstract}

Keywords: Bed roughness; density currents; density evaluation; image analysis technique; lock-exchange experiments

\section{Introduction}

Gravity or density currents are flows driven by buoyancy differences between two fluids, which can be caused by gradients in temperature, dissolved substances or particles in suspension. Gravity currents include a wide range of geophysical flows occurring spontaneously in nature or resulting from human intervention. In the atmosphere, thunderstorms outflows and sea-breeze fronts are gravity currents driven by differences in temperature, whereas avalanches of airborne snow, plumes of pyroclasts from volcanic eruptions and sand storms are atmospheric flows where suspended particles play a major role in density gradients. Oceanic fronts result from differences in temperature and salinity, and turbidity currents are caused by high concentrations of suspended particles. Though gravity currents are a major issue in geophysics (Simpson 1997), they are also important in engineering, particularly in industrial safety and environmental protection. The release of pollutants into rivers, oil spillage in the ocean and desalination plant outflows are a few examples of anthropogenic gravity currents, frequently with negative environmental impacts. The loss of storage in reservoirs, related to deposition of fine sediments due to turbidity currents, is a subject of great concern to hydraulic engineers and still a topic of research (Kostic and Parker 2003, Alves et al. 2008, Khavasi et al. 2012); several measures have been applied over the years to control sedimentation in reservoirs (Fan and Morris 1992, Kantoush et al. 2010) and innovative solutions are being investigated, such as the placement of obstacles in the flow bed as a mitigation measure against sedimentation (Oehy and Schleiss 2007, Rossato and Alves 2011) and by exploring alternative methods to release sediments out of reservoirs (Althaus et al. 2011). Field data acquired in reservoirs provide insight

Revision received 18 April 2013/Open for discussion until 31 January 2014.

ISSN 0022-1686 print/ISSN 1814-2079 online

http://www.tandfonline.com 
into the phenomenon of gravity currents and help develop mitigation measures. This also provides valuable information in the investigation of entrainment between current and ambient fluid, particularly in the validation of entrainment laws (Fernandez and Imberger 2006, García et al. 2007). Cenedese and Adduce(2008, 2010) focused on both the evaluation of entrainment and formulation of an entrainment relation considering a large amount of both field and laboratory data.

Gravity currents have been studied extensively in the laboratory through lock-exchange experiments (Huppert and Simpson 1980, Rottman and Simpson 1983, Altinakar 1993, Hallworth et al. 1996, Zhu et al. 2006) which consist of the instantaneous release of a fixed volume of dense fluid into another fluid of slightly lower density. The differences in hydrostatic pressure between fluids cause the denser fluid to flow along the bottom boundary of the channel, while the lighter fluid flows along the top boundary, in the opposite direction. The development of gravity currents is typically an unsteady phenomenon, i.e. current kinematics and inner density distribution are time varying. Therefore, the lock-exchange setup is a simple and convenient way to investigating the flow features of these particular currents. Numerical modelling has also been used to investigate the evolution and impact of gravity currents (Härtel et al. 2000, Cantero et al. 2007, Ooi et al. 2007, Bombardelli et al. 2009, Paik et al. 2009, Gerber et al. 2011, Tokyay et al. 2011, Adduce et al. 2012, La Rocca et al. 2012b, a). Although the motion of these currents is invariably three-dimensional, laboratorial experiments and numerical results indicate that the large-scale features may be reasonably well described through a two-dimensional approach (Härtel et al. 2000).

Several laboratory studies have been based on image analysis techniques to investigate the dynamics of gravity currents (Hacker et al. 1996, Shin et al. 2004, Marino et al. 2005, La Rocca et al. 2008, Adduce et al. 2012, the last two with the very same apparatus herein used). Recent advances in measurement techniques have enabled velocity and density measurements within gravity currents. Particle image velocimetry (PIV) and particletracking velocimetry (PTV) have been used to investigate the inner velocity field of the current (Alahyari and Longmire 1996, Thomas et al. 2003, Zhu et al. 2006, Adduce et al. 2011) and the combination of PIV with other methods, such as laser-induced fluorescence (LIF) (Parsons and García 1998, Martin and García 2009) and PIV-S (Gerber et al. 2011), allow for the simultaneous measurement of velocity and density.

Most of the investigation efforts concern flows developing over smooth beds, though a few investigators have studied the effect of bed roughness in the dynamics of gravity currents. Peters and Venart (2000) used LIF to investigate flow dynamics and mixing processes at the head region of gravity currents developing over rough surfaces. They used regular square cross-section elements to reproduce bed roughness, spanning the full channel width, with four different side dimensions. In general, they observed that roughness decreases the front velocity and induces higher dilution in the head region. According to these authors, those effects are due to two mechanisms: an increase in bed roughness induces extra bed shear stress, extra flow resistance and viscous effects; additionally, ambient fluid trapped within the roughness layer is entrained into the current, contributing to a reduction of the buoyancy differences between current and ambient fluid which constitutes the flow driving force. In La Rocca et al. (2008), three-dimensional gravity currents were produced by varying the initial density of the mixture in the lock and the bed roughness of the tank, testing four mean diameters within a range of $0.7-3.0 \mathrm{~mm}$ in a thin layer glued to the bed. The front velocity was seen to decrease with the increase of the mean diameter of the roughness elements, this effect being more obvious in the second phase of the current development. The increase in the friction stress induced by roughness precedes the beginning of the current deceleration phase. Adduce et al. (2009) performed experiments with a rough bed using quartz sand. They used an image analysis technique to investigate current dynamics and confirmed the findings reported in both Peters and Venart (2000) and La Rocca et al. (2008) regarding roughness effects on front velocity reduction. The effect of bed roughness in the development of gravity currents, developing downslope in the ocean and important in ocean circulation, was numerically investigated by Özgökmen and Fischer (2008). The results of their simulations suggest that roughness enhances drag, with effects on the velocity field, and mixing between the current and ambient fluid modifying the density distribution within the current. Despite previous contributions, the effect of the bed roughness in the kinematics of gravity currents is far from being completely understood.

Gravity currents produced by the lock-exchange technique over a smooth bed present two, or even three, distinct phases: slumping phase, self-similar phase and viscous phase (Huppert and Simpson 1980, Rottman and Simpson 1983). According to Huppert and Simpson (1980), after the instantaneous release, simulated by means of a sudden gate removal, an initial adjustment phase is observed during which the front position varies linearly with time, i.e. the front advances with approximately constant velocity. In the case of lock-exchange experiments, when the flow is confined within a channel of limited length, the initial constant-velocity phase merges into a second phase, or self-similar phase, when a bore generated at the end wall of the channel overtakes the front (Rottman and Simpson 1983). From this instant, the front position advances as $t^{2 / 3}$, with front speed decreasing as $t^{-1 / 3}, t$ being the time after the gate removal. In both slumping and self-similar phases, the current development is governed by the balance between buoyancy and inertial forces. When viscous effects overcome inertial effects, a third phase develops and the current front velocity decreases more rapidly (as $t^{-4 / 5}$, with front position advancing as $t^{1 / 5}$ ). Peters and Venart (2000) reported that viscous effects dominate the flow earlier in the presence of a rough bed, when compared to smooth bed experiments. Generally, buoyancy is the engine for gravity current propagation. Buoyancy forces are in turn counterbalanced by inertia as well as resistance due to Reynolds stresses and 
viscous drag, both acting at the upper and lower boundaries of the current.

The present work aims to (i) investigate the influence of the density of the fluid in the lock and of the bed roughness on the gravity current development and (ii) analyse characteristic variables for each phase of the current by comparing different kinematic scales, bulk and local (the latter characterizing the current head), for normalization of the front velocity. This research is based on experimental work where lock-exchange density currents, induced by salinity differences, are reproduced under controlled conditions in an open channel. The development of the saline currents is captured by a CCD camera, using dye concentration as a tracer, thus allowing for the reconstruction of time and space (2D) evolution of the density fields. The assessment of the density fields through the image analysis technique herein presented contains information supplementary to previous works on gravity currents, specifically the works by LaRocca et al. (2008), with gravity currents developing over rough beds, and Adduce et al. (2012), with gravity currents developing over smooth beds.

After this introduction, experimental details are given in Section 2, main results concerning flow visualization, front position and velocity, current height and depth-averaged density are presented and discussed in Section 3 and Section 4 is devoted to the main conclusions.

\section{Experimental details}

\subsection{Apparatus and experimental procedure}

The lock-release experiments were performed in a rectangular cross-section tank, with horizontal bed, $3.0 \mathrm{~m}$ long, $0.2 \mathrm{~m}$ wide and $0.3 \mathrm{~m}$ deep (Fig. 1) with transparent Perspex walls at the

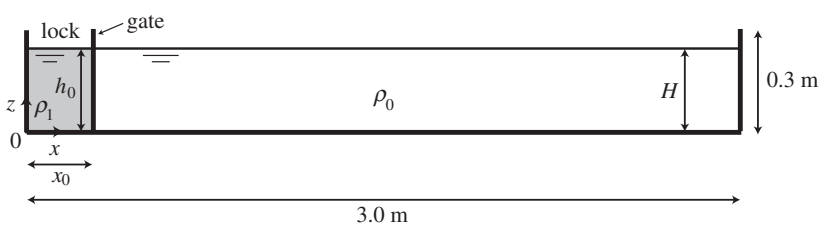

Figure 1. Schematic view of the Perspex tank aimed at the lock-exchange experiments with main dimensions and the Cartesian reference system herein considered
Hydraulics Laboratory of University Roma Tre (Nogueira et al. 2013). The saline mixture with initial density $\rho_{1}$ was placed in a lock with a vertical sliding gate at a distance $x_{0}=0.15 \mathrm{~m}$ from the upstream section, i.e. left wall, of the tank. The right side of the tank was filled with fresh water with density $\rho_{0}$, both sides filled up at same depth, $h_{0}$. In the experiments with bed roughness, $h_{0}$ was measured from the top of the bed crests. In all experiments, the relative depth of the initial configuration was kept $h_{0} / H=1$, where $H$ is the total depth of the ambient fluid.

The density of the fresh water in the tank, $\rho_{0}$, and of the saline mixture in the lock, $\rho_{1}$, was obtained in the beginning of each run. Temperature measurements were performed in both fluids and a pycnometer was used to determine the density of the saline mixture (the error of the apparatus is $0.05 \%$ ). The density difference between fluids is a result of both temperature and brine concentration. Density values are presented in Table 1 . The kinematic viscosity of the saline mixture, $v$, is a function of temperature, pressure and concentration of salt, and is obtained through the results presented in Kestin et al. (1981). A controlled quantity of white colorant (E171, titanium dioxide) was added to the mixture in the lock for flow visualization. The experiment started when the gate was suddenly removed leading to the collapse of the vertical column of heavier fluid, forming a heavier gravity current developing along the tank bed, while a lighter density current formed by ambient fluid develops above the denser current in the opposite direction. During this process, mixing between both currents takes place, inducing entrainment of ambient fluid into the heavier density current, reducing its density. The experiment ends when the current reaches the right end wall of the tank. To visualize the current, high contrast between the current and its background was achieved through the placement of black paperboard in the back wall of the tank, producing a dark, uniform background. The evolution of the gravity current was recorded with a CCD video camera with $768 \times 576$ pixels of resolution and acquisition frequency of $25 \mathrm{~Hz}$. The camera was kept at a fixed perpendicular position $5.8 \mathrm{~m}$ from the tank and aligned with its centre to capture the entire tank length. A metric scale is positioned in both horizontal and vertical directions of the tank and used for geometric calibration. No special lighting except fluorescent ceiling lighting was used to illuminate the flow. During the experiments, the upper part of the tank was covered with a thin black painted wooden board to avoid reflection of light from the water surface. The captured video frames were subsequently

Table 1 Main parameters of the experimental runs

\begin{tabular}{lcccccccccc}
\hline Run & $\rho_{0}\left(\mathrm{~kg} \mathrm{~m}^{-3}\right)$ & $\rho_{1}\left(\mathrm{~kg} \mathrm{~m}^{-3}\right)$ & $k_{s}(\mathrm{~mm})$ & $g_{0}^{\prime}\left(\mathrm{ms}^{-2}\right)$ & $u_{0}\left(\mathrm{~ms}^{-1}\right)$ & $\bar{u}_{f}\left(\mathrm{~ms}^{-1}\right)$ & $\mathrm{R}_{0}$ & $\mathrm{R}_{\mathrm{b}}$ & $\mathrm{F}_{\mathrm{b}}$ & Symbols in figures \\
\hline D1 & 997.8 & 1014.7 & 0.0 & 0.17 & 0.18 & 0.06 & 40,756 & 3872 & 1.31 \\
D2 & 997.4 & 1029.7 & 0.0 & 0.32 & 0.25 & 0.09 & 53,230 & 5716 & 1.31 & $\circ$ \\
D3 & 997.4 & 1044.6 & 0.0 & 0.46 & 0.30 & 0.11 & 66,918 & 7237 & 1.55 & $\square$ \\
D4 & 998.0 & 1060.0 & 0.0 & 0.61 & 0.35 & 0.12 & 64,680 & 8244 & 1.66 & $\nabla$ \\
R1 & 997.4 & 1030.0 & 2.9 & 0.32 & 0.25 & 0.08 & 64,922 & 5647 & 1.59 & + \\
R2 & 997.4 & 1030.1 & 4.6 & 0.32 & 0.25 & 0.08 & 55,058 & 5283 & 1.54 & $\times$ \\
R3 & 997.6 & 1030.2 & 24.6 & 0.32 & 0.25 & 0.07 & 52,479 & 4385 & 0.89 & $*$ \\
\hline
\end{tabular}




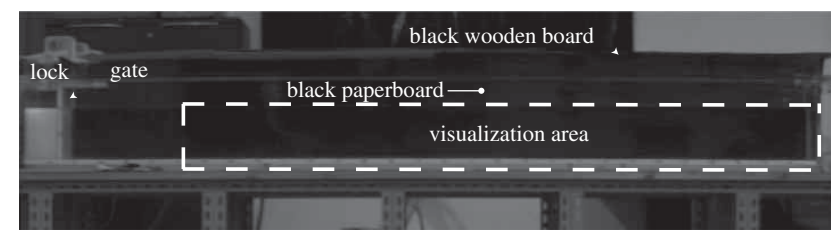

Figure 2. Lateral view of the tank and region analysed in detail further in the text

converted into grey scale matrices in the region of the tank with fluid $(702 \times 43$ pixels) and then converted into instantaneous density fields through a calibration procedure. Results are shown for a selected window (dashed rectangle in Fig. 2) of the field of view.

The evaluation of the current density distribution was based on a relation between reflected light intensity and concentration of dye present in the flow; the latter is considered linearly correlated with the salt concentration within the current body. A calibration procedure was carried out for each single pixel in the region defined earlier to establish the relation between the amount of dye in the water and the values of grey scale in the frames representing light intensities. Eight successive additions of known dye quantities, increasingly from zero to a maximum value corresponding to $\rho_{1}$, were uniformly distributed through the tank. The corresponding images were captured for calibration with the very same light conditions and distance between camera and tank as during the experiments. Only dye dissolutions was used to obtain the calibration curves since it was observed that dissolved salt did not change the grey scale values in the acquired frames. Grey scale values increase nonlinearly with the amount of dye in the flow (cf. calibration curve for one pixel presented in Nogueira et al. 2013). Assuming a direct relation between the amount of dye and density of the current, it is thus possible to infer density values at any given pixel and at any given instant from its instantaneous grey scale value through a cubic interpolation applied to each individual pixel calibration curve. Oscillations in the intensity of the ambient light were detected when analysing the temporal series of grey scale values in each pixel of a selected region in the acquired frames; in terms of density, those deviations are below $6 \%$. The results obtained from the technique used herein were then verified and eventually corrected through total salt mass conservation principle applied to the entire experimental tank. This correction covers overall experimental and data treatment errors and proves to be of the order of magnitude of $0.1 \%$, i.e. the relative deviation between the total mass in the tank, considering the amount of water $\left(m_{0}\right)$ and salt $\left(m_{s}\right)$ introduced in the tank in the beginning of the experiment $\left(m_{s}+m_{0}\right)$, and the total mass evaluated experimentally $\left.\left(w\left(\int_{A_{c}} \rho(x, z, t) \mathrm{d} A+\int_{A_{0}} \rho_{0} \mathrm{~d} A\right)\right)\right)$, where $w$ is the width of the tank, $\rho(x, z, t)$ is the local density of the current, $A_{c}$ and $A_{0}$ are the volumes of the gravity current and the ambient fluid per unit width of the tank, respectively, and $A$ the volume considered per unit width of the tank.

The conversion of grey scale video images into density fields is illustrated by Fig. 3 which shows a photo of the current acquired

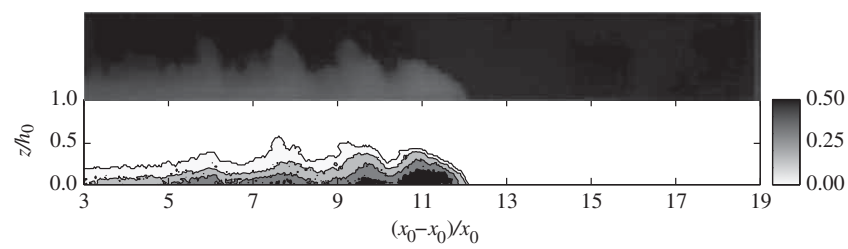

Figure 3. (Top) Photo of the current acquired at $t=28 \mathrm{~s}$ after the gate removal in run D1 and (bottom) corresponding non-dimensional iso-density contours plotted at $\rho^{*}=0.02,0.15,0.30$ and 0.50

at $t=28 \mathrm{~s}$ after the gate removal in run D1 (experimental runs defined in Table 1) and the corresponding reconstructed nondimensional iso-density contours plotted for $0.02,0.15,0.30$ and 0.50 , with the instantaneous non-dimensional density defined as $\rho^{*}(x, z, t)=\left(\rho(x, z, t)-\rho_{0}\right) /\left(\rho_{1}-\rho_{0}\right)$. The density current presented in Fig. 3 presents three regions, near-bed region where bed drag exerts influence mainly on momentum transfer related processes, central region where velocity is expected to be maximum and little mass and momentum transfer processes are verified and interfacial shear layer, the main region for mass and momentum transfer (Legg 2012).

\subsection{Experiments}

Seven lock-exchange experiments were performed varying the initial density of the saline water in the lock, $\rho_{1}$, and the bed roughness, $k_{s}$, leading to two different types of runs: D and R, respectively. The experiments were performed by varying one parameter at a time. Table 1 summarizes the parameters of the experiments and the symbols used in the figures. Each run was performed with an initial reduced gravity of the mixture in the lock, defined as

$$
g_{0}^{\prime}=g \frac{\rho_{1}-\rho_{0}}{\rho_{0}}
$$

$g$ being the acceleration of gravity. The main parameters are presented in the non-dimensional form by adopting the following dimensionally independent scales, in accordance with previous studies (Hacker et al. 1996, Marino et al. 2005): lock length $x_{0}$ as length scale and a velocity scale given by the buoyancy velocity defined as

$$
u_{0}=\sqrt{g_{0}^{\prime} h_{0}}
$$

The Reynolds number based on initial quantities, $R_{0}=$ $u_{0} h_{0} / v$ is also presented in Table 1 showing the turbulent nature of the gravity currents performed since $R_{0}>40,000$. Both densimetric Froude, $F_{b}$, and Reynolds, $R_{b}$, numbers based on bulk quantities of the current are also presented in Table 1, $\mathrm{F}_{\mathrm{b}}=\bar{u}_{f} / \sqrt{g \Delta \rho / \rho_{0} \bar{h}}$, where $\bar{u}_{f}$ is the bulk front velocity of the current, obtained by considering the initial and final configurations of the current and the duration of the experiment (cf. Table 1); $\Delta \rho=\rho_{f}-\rho_{0}$, with $\rho_{f}$ the mean density of the gravity current in its final configuration, i.e. when it reaches the end of the tank, and $\bar{h}$ the bulk height of the current, taken as 

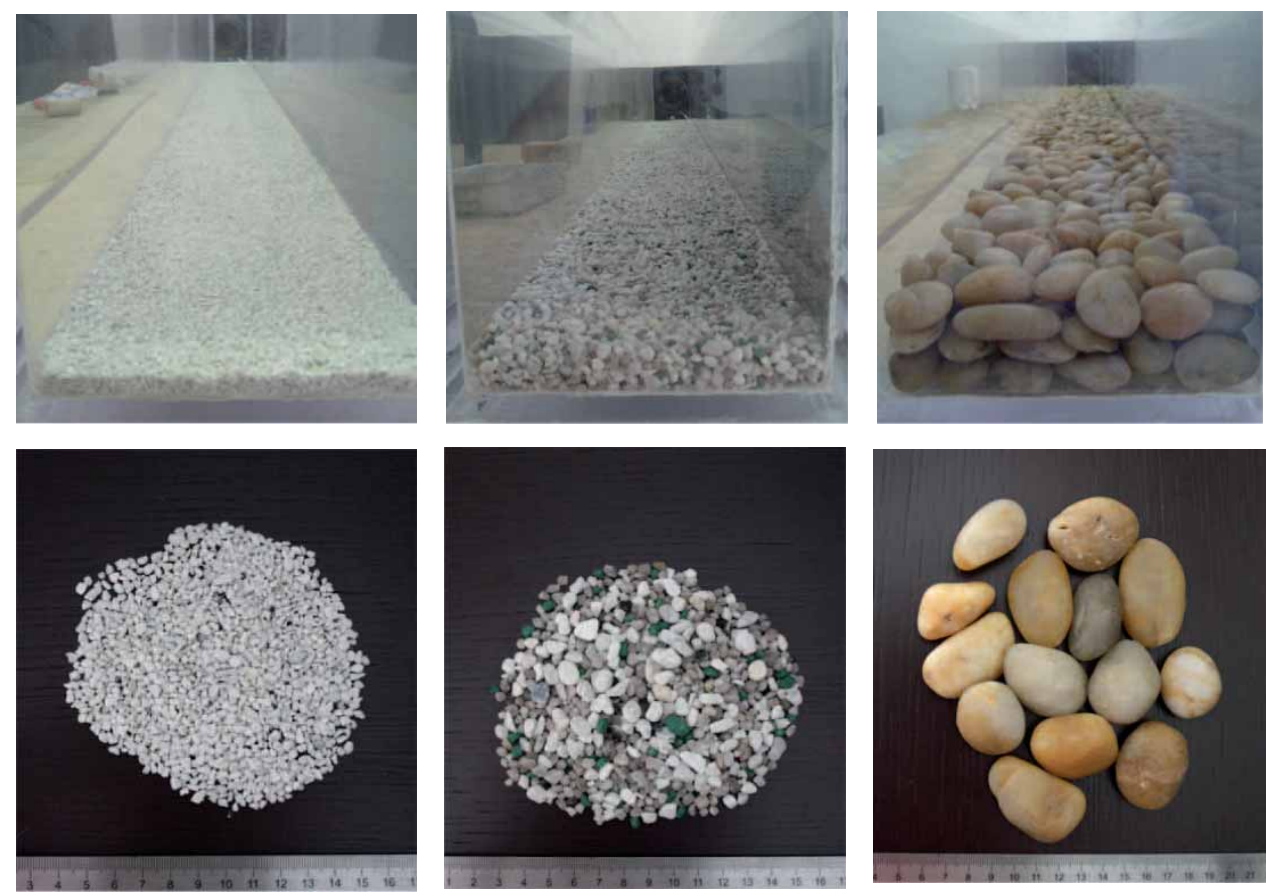

Figure 4. Details of the rough beds used for runs of type R: R1 (left), R2 (centre) and R3 (right). View of the tank bed from the downstream section, i.e. right end wall (top) and sediment samples (bottom)

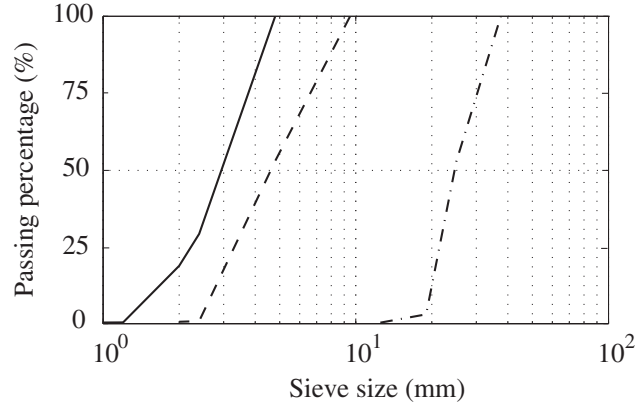

Figure 5. Granulometric curves of the sediments used in runs R1 (solid), R2 (dashed) and R3 (dashed-dot)

Table 2 Characteristics of the sediments

\begin{tabular}{lcccc}
\hline Run & $D_{10}(\mathrm{~mm})$ & $D_{30}(\mathrm{~mm})$ & $D_{50}(\mathrm{~mm})$ & $D_{60}(\mathrm{~mm})$ \\
\hline R1 & 1.6 & 2.4 & 2.9 & 3.2 \\
R2 & 2.7 & 3.5 & 4.6 & 5.2 \\
R3 & 19.8 & 22.1 & 24.6 & 26.6 \\
\hline
\end{tabular}

$\bar{h} \approx 1 / 3 h_{0}$ based on the results presented further in the text. Bulk Reynolds number was obtained through $\mathrm{R}_{\mathrm{b}}=\bar{u}_{f} \bar{h} / \nu$.

The rough bed in R-type experiments was made by placing a thick layer of sediments throughout the tank bed, as shown in Fig. 4. The sediment in the tank was made in order to create a layer with thickness of around $3 D_{50}$, where $D_{50}$ is the grain size diameter for which $50 \%$ of the of sediment has smaller diameter. Herein, $D_{50}$ was taken as the roughness scale $k_{s}$. The tank was levelled horizontally and the grains were set uniformly throughout the tank; no bed forms were allowed. Figure 5 shows the granulometric curves and Table 2 summarizes the characteristics of the sediments used.

\section{Results}

\subsection{Front position}

The instantaneous front position $x_{f}(t)$ was estimated through the instantaneous density maps by taking the $x$-position of the foremost point of the current and by adopting the nondimensional iso-density contour of 0.02 as the boundary of the current. The amplitude of the error of the front position corresponds to a half pixel $( \pm 2 \mathrm{~mm})$ in space and to half the camera sampling time $(0.02 \mathrm{~s})$ in time. Figure 6 a shows the variation with time of the front position in terms of lock lengths, $\left(x_{f}-x_{0}\right) / x_{0}$, and Fig. $6 \mathrm{~b}$ the corresponding log-log plot for all runs including the regression curves found in literature for both slumping and self-similar phases.

Figure 6 shows data collapsing when front position and time are normalized by the geometric and kinematic parameters introduced earlier. Generally, two distinct phases were observed during the development of the gravity current: (i) a first slumping phase, characterized by a linear relation between front position and time after the gate removal and ii) a second phase, or selfsimilar phase, in which the current moves under the balance between buoyancy and inertial forces, with the front position a nonlinear function of time. Run R3 shows, however, deviation from the general trend of the remaining runs which is more evident during the second phase of the current development, as also observed by La Rocca et al. (2008) when analysing the effect of bed roughness on the front propagation.

According to the literature (i.e. Rottman and Simpson 1983), a linear phase takes place until $\left(x_{f}-x_{0}\right) / x_{0} \approx 9$, which is confirmed by the general trend observed in Fig. 6. Run R3, 

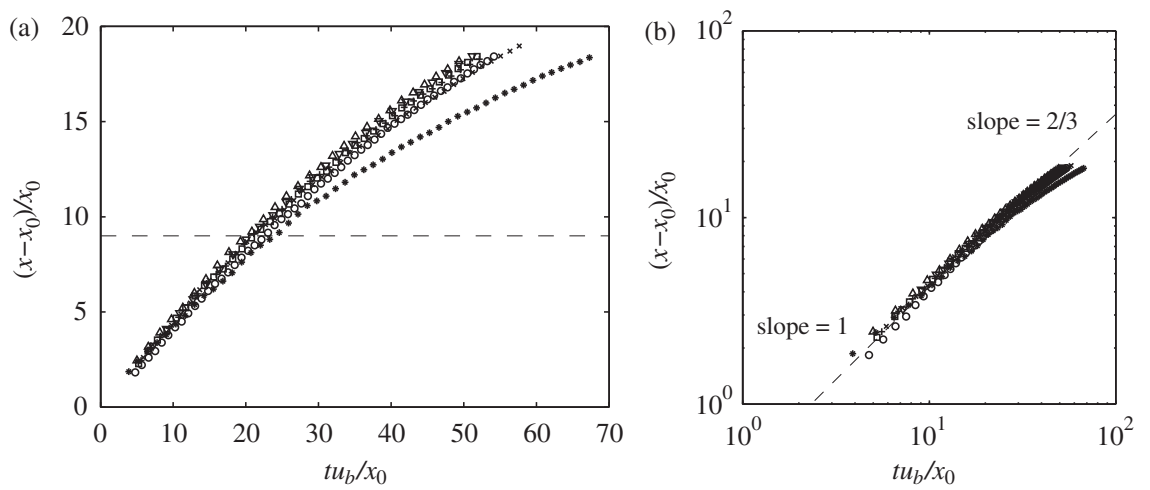

Figure 6. Temporal evolution of the non-dimensional current front position for each run: (a) normal scale and (b) logarithmic scale (symbols explained in Table 1)

Table 3 Main parameters of the two phases of the current development identified on the lock-exchange experiments

\begin{tabular}{lcccccrrr}
\hline \multicolumn{3}{c}{ Run } & \multicolumn{3}{c}{ Linear phase } & \multicolumn{3}{c}{ Nonlinear phase } \\
\cline { 2 - 8 }$t_{f_{1}} u_{0} / x_{0}(-)$ & $\left(x_{f_{1}}-x_{0}\right) / x_{0}(-)$ & $u_{f_{1}}\left(\mathrm{~ms}^{-1}\right)$ & $u_{f_{1}} / u_{0}(-)$ & $r^{2}(-)$ & $a(-)$ & $b(-)$ & $r^{2}(-)$ \\
\hline D1 & 20.8 & 8.5 & 0.07 & 0.41 & 0.9993 & 0.74 & 0.81 & 0.9982 \\
D2 & 14.7 & 6.6 & 0.11 & 0.46 & 0.9993 & 0.74 & 0.81 & 0.9986 \\
D3 & 18.1 & 8.4 & 0.14 & 0.47 & 0.9964 & 0.90 & 0.78 & 0.9987 \\
D4 & 20.4 & 9.1 & 0.16 & 0.45 & 0.9979 & 0.87 & 0.78 & 0.9990 \\
R1 & 21.3 & 9.3 & 0.11 & 0.44 & 0.9977 & 0.91 & 0.76 & 0.9985 \\
R2 & 21.4 & 9.3 & 0.11 & 0.44 & 0.9967 & 1.01 & 0.73 & 0.9983 \\
R3 & 6.8 & 3.1 & 0.12 & 0.48 & 0.9835 & 0.78 & 0.76 & 0.9947 \\
\hline
\end{tabular}

however, has a shorter linear phase, the transition to a second phase occurring earlier than the remaining runs, which leads to the conclusion that scales related to bed roughness and possibly to bed porosity may play a role in the current kinematics. As argued by Peters and Venart (2000), extra resistance due to bed shear stress of rougher beds combined with a reduction of the current buoyancy due to entrainment of ambient fluid at the bed level may cause an earlier end of the first phase. Therefore, for a proper normalization of front position in time, an additional parameter, taking into account the roughness of the bed material, is needed.

Transition points between linear and nonlinear phases were estimated by applying a linear regression to $x_{f}(t)$ data by a leastsquares approach. The nonlinear phase was adjusted by a power law of type $\left(x_{f}-x_{0}\right) / x_{0}=a\left(t u_{0} / x_{0}\right)^{b}$, where coefficients $a$ and $b$ were obtained through a least-squares regression applied after data linearization. The coefficient of determination, $r^{2}$, was used to evaluate the goodness of fit. Table 3 summarizes the main parameters of each phase for all runs, where $t_{f 1}$ and $x_{f 1}$ are the time and space coordinates corresponding to the transition between linear and nonlinear phases and $u_{f 1}$ the constant velocity during the first phase. Values of front velocity shown here were obtained by derivation in time of the regression function adjusted to the linear phase.

In the slumping phase, front velocity is roughly constant, the average being a non-dimensional value, normalized by the buoyancy velocity (cf. Eq. 2), $u_{f 1} / u_{0}=0.46 \pm 0.02$ for all the runs, in agreement with previous results (Rottman and Simpson
1983, Marino et al. 2005). Transition between slumping and self-similar phases were obtained in the range $\left(x_{f}-x_{0}\right) / x_{0}=$ $8.4 \pm 1.0$, which is in accordance with previous observations. The earlier end of the linear phase observed for run R3 does not affect the propagating velocity of the current during the initial phase. Nevertheless, in the first instants of the current, buoyancy and inertial effects seem to still be balanced, indicating that both mechanisms originated by the rougher bed, i.e. current deceleration due to extra bed drag and extra entrainment at the bed level, did not produce effect at that stage. Both the rough scale and the porosity of the bed material may play a role in the current kinematics, although in the present case, given that the current dilution in run R3 is similar to run D2 (see discussion in Section 3.2), the main effect on delaying the current front velocity is produced by the extra bottom drag. Although 3D gravity currents were seen to have different kinematic behaviours in the first phase (La Rocca et al. 2008), since the reflected bore could not reach the current front due to geometric constraints, an early transition to a second phase of decreasing velocity was still detected when increasing the bed roughness. Moreover, roughness effect is more visible in the second phase.

During the second phase, a deceleration of the flow was observed converging to the front evolution typical of the self-similar phase of lock-exchange experiments when finally the upstream bore arrived at the front. Linearized front position data collapse well and consistently around straight lines with slopes in the range $0.73-0.81$ (Table 3 ), with an average value of 0.78 (excluding test R3), slightly higher than the value of $2 / 3$ 

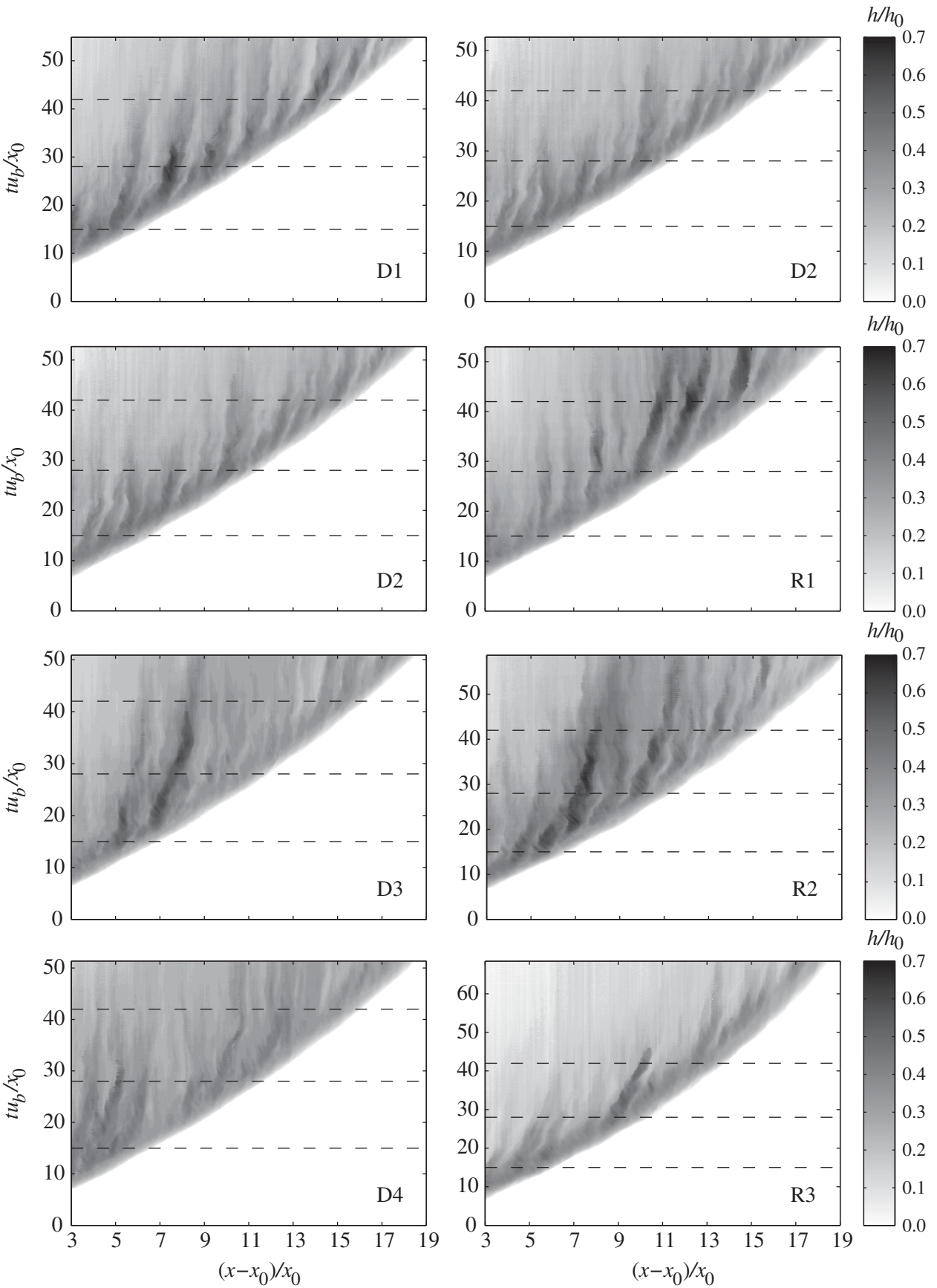

Figure 7. Time-space evolution of the non-dimensional current height $h / h_{0}$. Left: runs with increasing initial density in the lock, $\rho_{1}$ and right: runs with increasing bed roughness, $k_{s}$. Horizontal dashed lines at $t u_{0} / x_{0}=15,28$ and 42 correspond to the instants represented in Figs. 9 and 10

predicted in the literature. The tank where the experiments were performed is $3.0 \mathrm{~m}$ long, thus no viscous phase was observed in accordance with previous results in the literature (Huppert 1982).

\subsection{Time-space varying current height and depth-averaged density}

Figure 7 shows the temporal evolution in the non-dimensional current height, $h / h_{0}$, where $h$ is the current height, along the $x$-axis for all runs performed. These plots show the signatures of the instabilities typically present in the mixing layer of the current (near vertical darker regions in Fig. 7), of which the imprint persists in time. These instabilities are quasi-stationary, or at least moving downstream at a different time scale than the remainder current, being slightly advected downstream (by drag effect) by the current mean velocity. These structures eventually fade in time and lose their signature by diffusive-type processes (Fig. 7, final instants).

The initial density of the saline mixture seems to influence the size and periodicity of the instabilities: for lower initial density (run D1) the instabilities show better definition, higher vertical length scale and more regular periodicity, when compared with the runs performed with higher initial density. The effect of the 

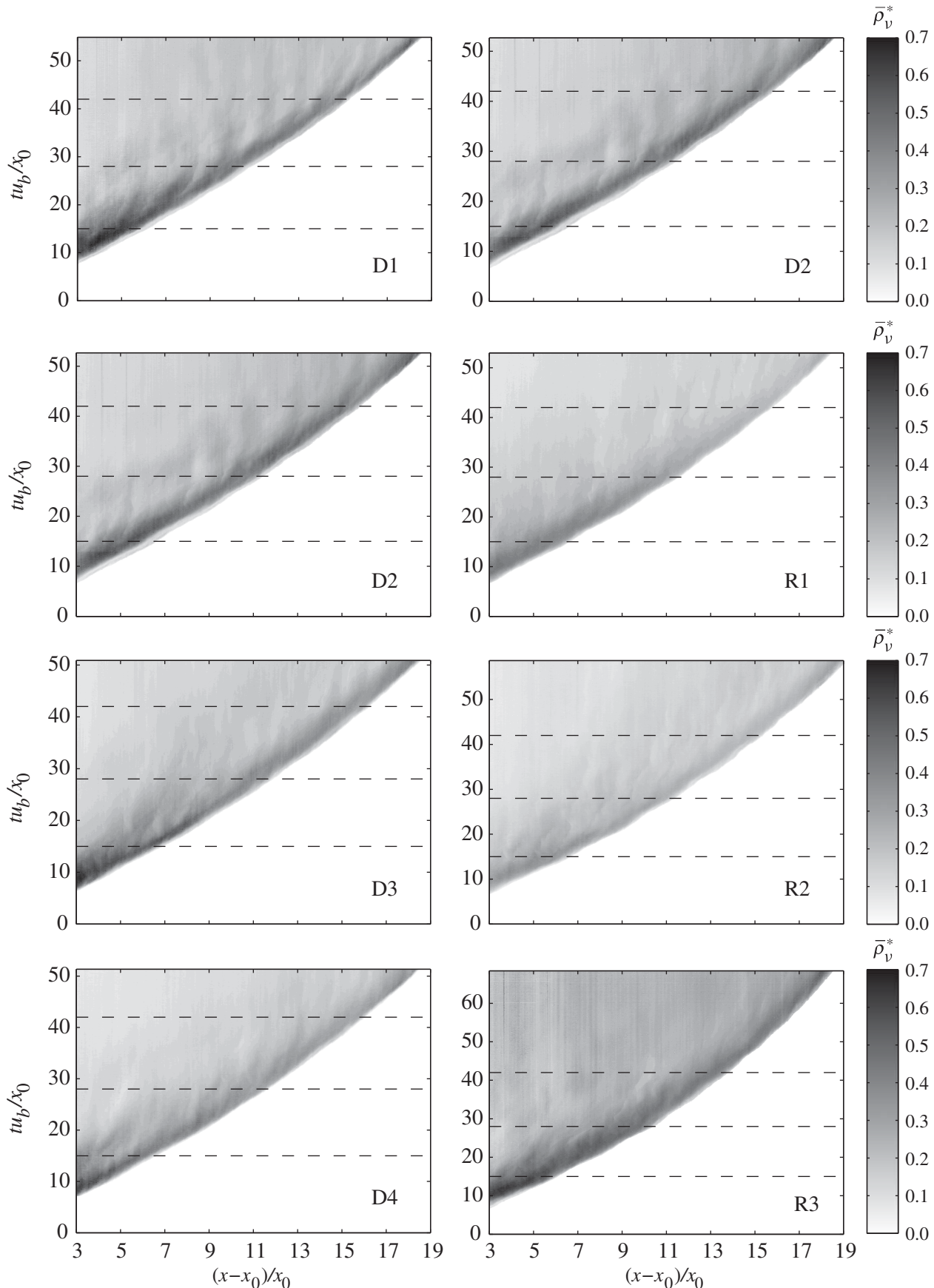

Figure 8. Time-space evolution of the non-dimensional current depth-averaged density $\bar{\rho}_{v}^{*}=\left(\overline{\rho_{\nu}}-\rho_{0}\right) /\left(\rho_{1}-\rho_{0}\right)$. Left: runs with increasing initial density in the lock, $\rho_{1}$ and right: runs with increasing bed roughness, $k_{S}$. Horizontal dashed lines at $t u_{0} / x_{0}=15,28$ and 42 correspond to the instants represented in Figs. 9 and 10

bed roughness is similar to the density one, i.e. bed roughness has a homogenizing effect throughout the current height: less evident billows, or with smaller length scale, were detected when the roughness scale is higher. In fact, preliminary PIV observations from similar experiments (Nogueira et al. 2012) indicate that larger bed roughness induces larger turbulent production in the lower levels, thus higher mixing within the current, justifying the homogenization of density throughout the depth.

Figure 8 shows the evolution in the depth-averaged current density in time along the $x$-axis for all runs performed.
Depth-averaged density was obtained by integrating the density within the current below its upper boundary defined by a threshold of excess density of $2 \%$. The depth-averaged density plots show in general a strongly diluted current in the region of analysis, the maximum of non-dimensional density being around 0.7. Differences in the density value, decreasing as the initial density increases, which are observed for instance when normalizing depth-averaged densities by the density of ambient fluid (not shown here), seem to suggest that the initial buoyancy plays an important role in the mixing process: as the initial buoyancy 
increases, a faster decay of current density was observed due to a stronger mixing between current and ambient fluid, as observed also by Cenedese and Adduce(2008, 2010). Figure 8 also shows, as expected, that the foremost region of the current, i.e. the current head, is the region in the entire current where higher density was observed (cf. Fig. 3).

Regarding the roughness effect, in general, as the bed roughness increases the front velocity decreases; it can be seen by observing the evolution in the front position in time (Figs. 6-8, sequence D2, R1, R2 and R3; the slope of the edge between white and grey regions represents the front velocity), which is in accordance with literature (Peters and Venart 2000, La Rocca et al. 2008, Adduce et al. 2009); the sequence D2, R1 and R2 of increasing roughness in Fig. 8 shows a gradual decrease in the depth-averaged density. However, for the highest roughness (run R3) that observation is not valid; in terms of density, no meaningful difference was observed when comparing with smooth bed (run D2). These observations suggest that bed roughness plays an important role in the current kinematics and the effect induced by the size of the roughness material needs further investigation.

\subsection{Height and depth-averaged density profiles}

For each run, profiles of non-dimensional current height for three selected time instants $\left(t u_{0} / x_{0}=15,28\right.$ and 42, shown in Figs. 7 and 8 with horizontal dashed lines) are plotted in Fig. 9. The effect induced by the increase in initial density in the lock is clear in the increase in the front velocity, as expected (Cantero et al. 2007). In general, current height does not seem to be influenced by the initial buoyancy or roughness: current height is kept quite the same over time, varying roughly between $0.3<h / h_{0}<0.5$. The instabilities identified in Fig. 7 are visible; both figures confirm their quasi stationary character and their disappearance mainly by diffusive-type processes. Figure 9 indicates as well that an increase in the initial density is related to a more stable mixing layer, i.e. with less evidence of large-scale billows. For each

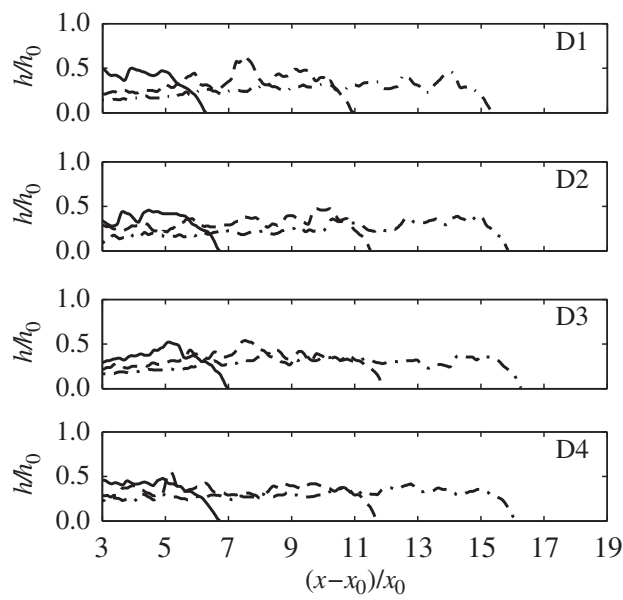

run, profiles of non-dimensional depth-averaged density for three selected time instants $\left(t u_{0} / x_{0}=15,28\right.$ and 42, shown in Figs. 7 and 8 with horizontal dashed lines) are plotted in Fig. 10.

As already observed in Fig. 8, the current head is the region within the current where the highest density was observed, in agreement with previous observations by Marino et al. 2005. The roughness effect, as already discussed in Section 3.2, induces a gradual decrease in the depth-average density (sequence D2, R1 and R2). Again, run R3 does not follow the decaying trend and exhibits values of the same order of magnitude of run D2. Runs performed with smooth bed (D-type runs) do not show relevant variations in time in the depth-averaged density. These differences are more evident when roughness is present. Generally, a slight temporal decay of density values in the head region was observed. As seen before, only run R3 shows an earlier decay in the front velocity caused by the extra bottom drag exerted by the larger bed roughness. The inertial-buoyancy equilibrium existing in the first stages of the current development is interrupted earlier, originating a concentration of mass in the head higher than in other cases. This is evident for instance in the plot corresponding to run R3 in Fig. 10, in which high values of concentration extend further upstream when compared with the other runs, explaining thus the lesser dilution observed already in Fig. 8. This justifies the earlier statement that, in this case, extra dilution of the current due to the entrainment of ambient fluid trapped within the bed porosity is not relevant here to current deceleration, when compared with the bed drag influence.

\subsection{Front velocity}

Time-varying densimetric Froude number, based on the front velocity, $u_{f}$, defined as

$$
\mathrm{F}=\frac{u_{f}}{\sqrt{g_{0}^{\prime} d}}
$$

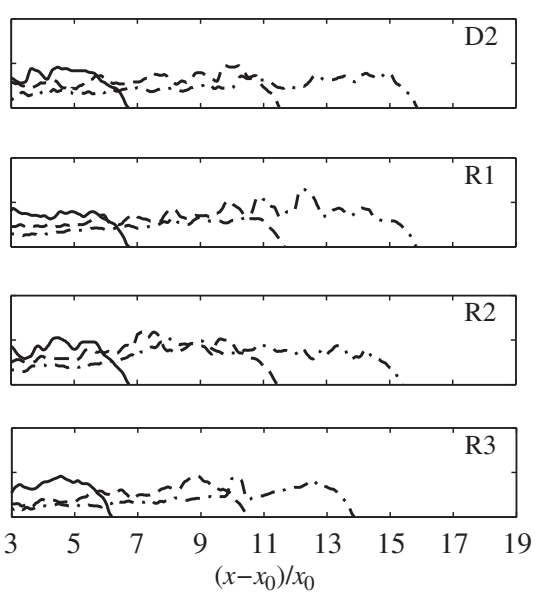

Figure 9. Time-space evolution of the non-dimensional current height $h / h_{0}$ at selected time instants $t u_{0} / x_{0}=15$ (solid), 28 (dashed) and 42 (dashed-dotted) (these instants are represented in Figs. 7 and 8 by horizontal dashed lines). Left: runs with increasing initial density in the lock, $\rho_{1}$ and right: runs with increasing bed roughness, $k_{s}$. Note that both $h$ and $h_{0}$ are measured from the top of the crests in the R-type experiments 

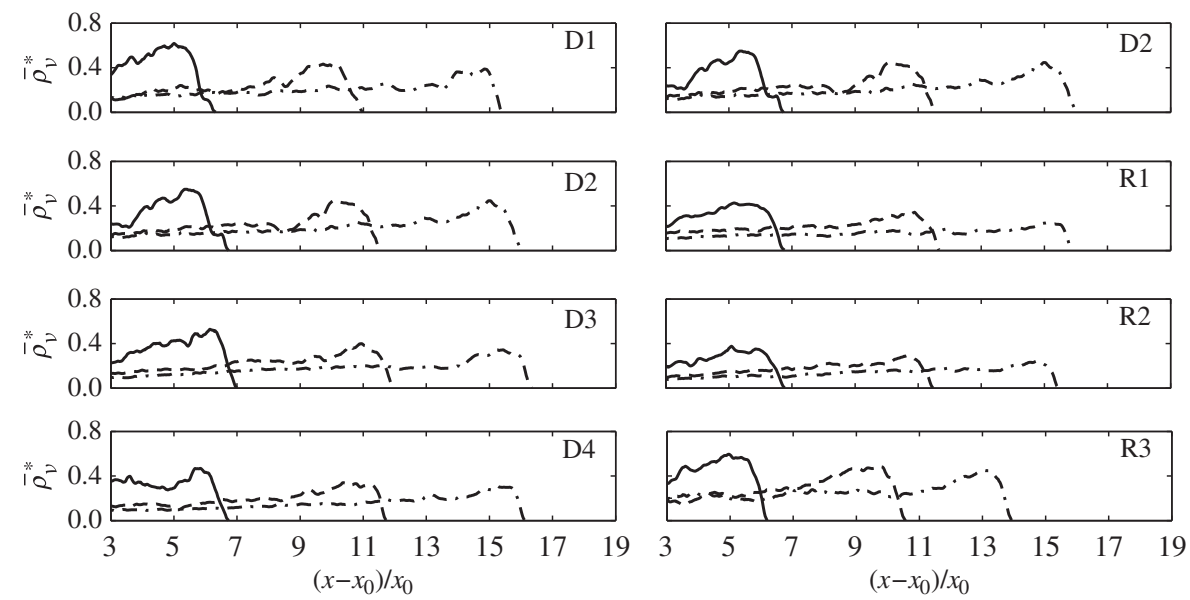

Figure 10. Profiles of the non-dimensional depth-averaged density at selected time instants $t u_{0} / x_{0}=15$ (solid), 28 (dashed) and 42 (dashed-dotted) (these instants are represented in Figs. 7 and 8 by horizontal dashed lines). Left: runs with increasing initial density in the lock, $\rho_{1}$ and right: runs with increasing bed roughness, $k_{s}$

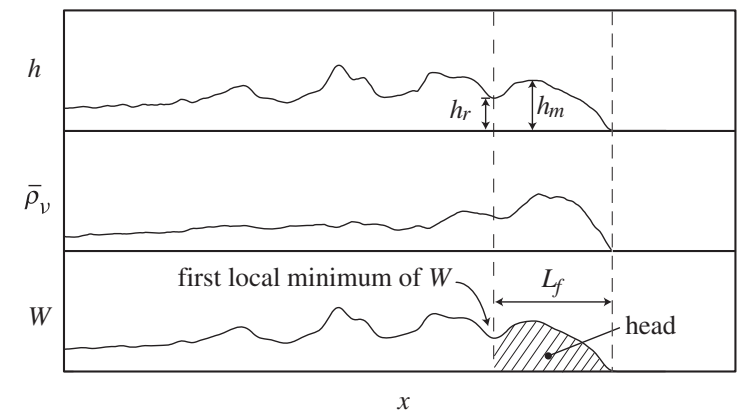

Figure 11. Definition of the head of the density current and its characteristic variables

was computed using three different length scales, i.e. characteristic depths, $d$, of the current: initial water depth in the lock, $h_{0}$, maximum height of the head, $h_{m}$ and height at the rear of the head, $h_{r}$ (see Fig. 11 for an explanation of the latter). Froude numbers so obtained were compared with local Froude numbers of the head region defined as

$$
F_{\text {head }}=\frac{u_{f}}{\sqrt{g_{\text {head }}^{\prime} d}}
$$

where $g_{\text {head }}^{\prime}$ is the local reduced gravity computed by using the head-averaged density of the current at each instant: $g_{\text {head }}^{\prime}=$ $g\left(\rho_{\text {head }}-\rho_{0}\right) / \rho_{0}$. Similarly, the very same three different depths were used as characteristic heights: $h_{0}, h_{m}$ and $h_{r}$.

To assess local parameters at the current head, a criterion to isolate this region of the current has been established. Previous contributions have shown that the head is the region where higher density is observed within the current (Hacker et al. 1996, Hallworth et al. 1996, Marino et al. 2005) which is in accordance with the results above discussed in Sections 3.2 and 3.3. Therefore, the criterion defined here to characterize and isolate this region is based on a dynamic function given by the product between local values of depth-averaged density and current height:

$$
W(x, t)=\bar{\rho}_{v}(x, t) h(x, t)
$$

which corresponds to local vertically-averaged mass of the current. The upstream limit of the head, and therefore the head length $L_{f}$, was defined by taking the position of the first meaningful local minimum of function $W$ (Eq. 5), near the front. Figure 11 shows a scheme of the current with the definition of the characteristic variables of the head.

Figure 12 shows Froude numbers computed for runs performed with smooth bed (runs D), with bulk initial reduced gravity (Eq. 3) and local reduced gravity (Eq. 4) (left and right, respectively), and using the three above mentioned characteristic heights $-h_{0}, h_{m}$ and $h_{r}$ (a-c and d-f, respectively). Velocities are taken from derivation of regression curves (Table 3 ) applied to $x_{f}(t)$ data.

In general, a good data collapse is observed using both initial and local reduced gravity (Fig. 12 left and right, respectively). An evident distinction between first and second current phases is observed in all plots; during the constant-velocity phase, $\mathrm{F}$ exhibits some scatter which is reduced in the self-similar phase.

Froude numbers estimated using $h_{0}$ and initial reduced gravity (Fig. 12a) show a constant plateau around 0.46 during the constant-velocity phase, in agreement with what is reported in literature (Shin et al. 2004, Marino et al. 2005). During the self-similar phase, $\left(x_{f}-x_{0}\right) / x_{0}>9$, Froude number $\mathrm{F}_{\mathrm{h}_{0}}$ starts to decrease. When using $h_{r}$ and $h_{m}$ as characteristic height (Fig. 12b,c), data collapses to a constant plateau of 0.6 during the second phase. Both results, with $h_{r}$ and $h_{m}$ are similar, only slightly different in terms of amplitude due to the evident differences in these geometric values (cf. Fig. 11). In terms of magnitude, $F_{h_{m}}$ and $F_{h_{r}}$ plateaus are slightly lower than the value reported in literature, 0.81 , when using the maximum height of the head (Marino et al. 2005). These differences may be explained by differences in the length scale used by these authors. 

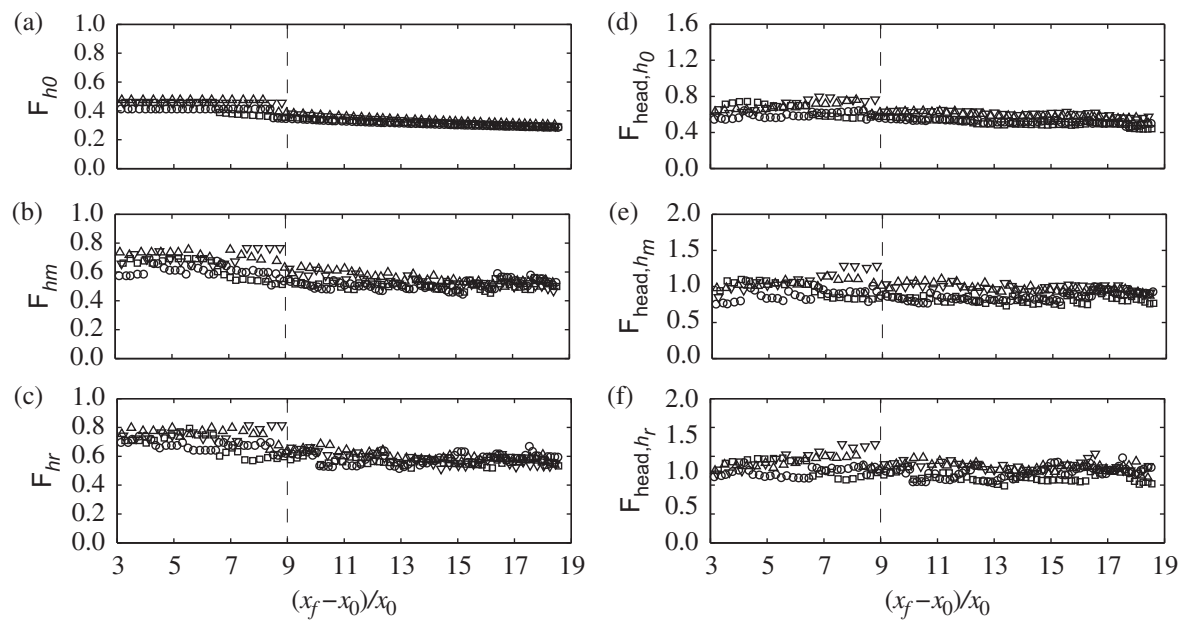

Figure 12. Evolution of Froude numbers considering (left) initial reduced gravity and (right) local reduced gravity, and using different characteristic heights defined as: (a) and (d) initial depth in the lock, $h_{0}$; (b) and (e) maximum height of the head, $h_{m}$ and (c) and (f) height at the rear of the head, $h_{r}$. Runs performed with smooth bed (D1, D2, D3 and D4). The limit of the first phase suggested in the literature of $\left(x_{f}-x_{0}\right) / x_{0}=9$ (Rottman and Simpson 1983) is indicated by vertical dashed lines (symbols explained in Table 1)

When normalizing by local reduced gravity (Fig. 12, right side), higher values of $\mathrm{F}$ are observed. Froude numbers estimated using $h_{0}$ (Fig. 12d) show a roughly constant plateau around 0.6 during the constant-velocity phase, decreasing gradually to $\left(x_{f}-x_{0}\right) / x_{0}>9$. Local Froude numbers based on $h_{m}$ and $h_{r}$ oscillate around 0.9 and 1.1, respectively, and a narrow collapse is observed during the self-similarity phase (Fig. 12e,f).

In general, observations show that after the constant-velocity phase current kinematics are ruled by the current head, i.e. the remaining body of the current does not play an important role in the current development. When using bulk quantities for the normalization of the front velocity (Fig. 12a), data collapses well around the expected value of 0.46 in the first phase indicating that at this early stage, the whole current body rules the front propagation. At this stage no apparent head detached from the remaining current is observed. The evolution of the current is governed by the bulk movement of the denser mass stored in the lock, indicating that buoyancy effects are given by the total body and its bulk parametrization. During the second phase, when the reflected bore catches the front of the current, the current is clearly fragmented into a body and a well-defined head with own momentum, penetrating in the ambient fluid. The front velocity is thus determined by this detached head, being in equilibrium with its buoyancy celerity, as concomitantly observed in Fig. $12 \mathrm{e}\left(\mathrm{F}_{\text {head, } \mathrm{h}_{\mathrm{m}}} \approx 1\right.$, thus $\left.u_{f} \approx \sqrt{g_{\text {head }}^{\prime} h_{m}}\right)$. Only when using all local variables to define Froude number (Fig. 12e,f), a plateau (and not a decreasing trend as seen in Fig. $12 \mathrm{~b}, \mathrm{c}$ ) is observed indicating the full dependency of the front velocity on the head dynamics. The fact that in the early stages of the current development no well-defined head exists may be responsible for the scatter observed in Froude numbers for $\left(x_{f}-x_{0}\right) / x_{0}<9$, when using local variables (Fig. 12d-f)
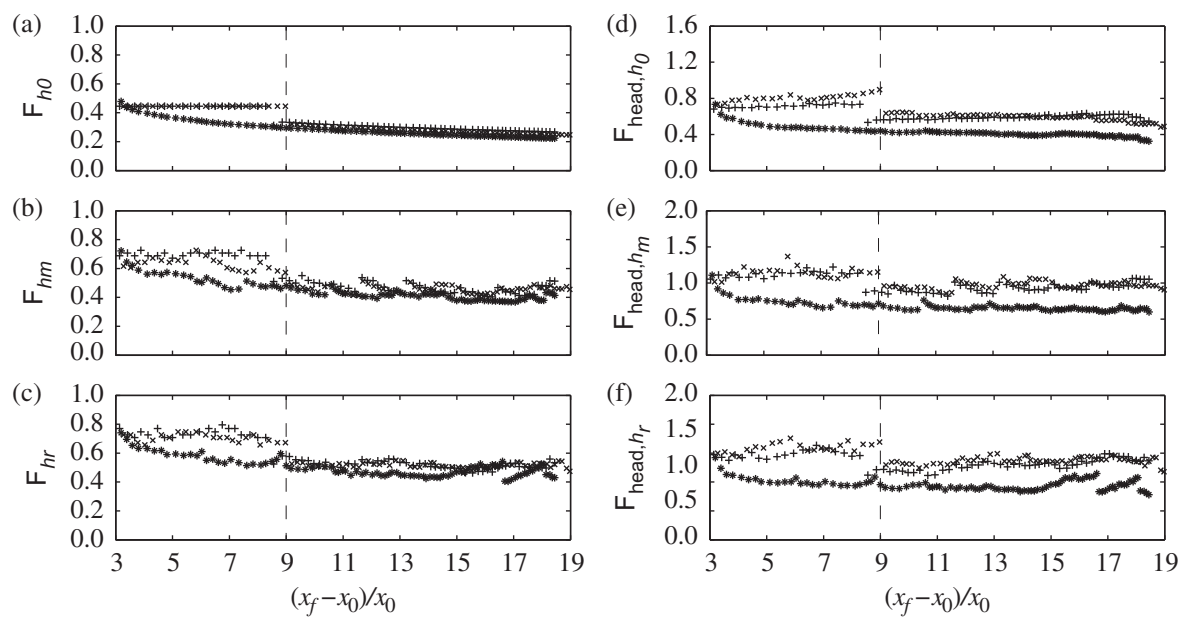

Figure 13. Evolution of Froude numbers considering (left) initial reduced gravity and (right) local reduced gravity, and using different characteristic heights defined as: (a) and (d) initial depth in the lock, $h_{0}$; (b) and (e) maximum height of the head, $h_{m}$ and (c) and (f) height at the rear of the head, $h_{r}$. Runs performed by changing the roughness of the bed (D2, R1, R2 and R3). The limit of the first phase suggested in the literature of $\left(x_{f}-x_{0}\right) / x_{0}$ $=9$ (Rottman and Simpson 1983) is indicated by vertical dashed lines (symbols explained in Table 1) 
which justifies the bulk character of the current propagation at this stage and, hence, local parametrization may not be adequate here.

Figure 13 shows Froude numbers concerning run D2 and runs of R-type, which show a similar trend observed in Fig. 12 for runs performed with smooth bed. These plots show again an evident deviation from run R3, which assumes, in general, lower Froude numbers. Figure 13a shows a constant plateau around 0.45 for runs R1 and R2, while run R3 exhibits a decreasing trend starting at the early stages of current development. During the second phase, data from the three experiments collapse and decrease at similar rate. Runs R1 and R2 show $F_{h_{m}}$ and $F_{h_{r}}$ data collapsing above 0.6 in the similarity phase when using initial reduced gravity (Fig. 13, left side). When normalizing by local reduced gravity (Fig. 13, right side), runs R1 and R2 show data collapsing around approximately constant values, independently from the stage of development of the current: $F_{h_{0}}=0.7, F_{h_{m}}=$ 1.0 and $\mathrm{F}_{\mathrm{h}_{\mathrm{r}}}=1.2$.

\section{Discussion and conclusions}

Gravity currents produced by lock-release of saline water into a finite open channel of horizontal bed, filled with an ambient fluid of fresh water, are presented and discussed as regards the evolution of the front position, the time and space evolution of the current height, as well as the depth-averaged density and front propagation velocity. Seven different experiments were performed by varying the initial density of the saline mixture in the lock and bed roughness, maintaining constant all the other experimental variables.

In general, all runs show the development of the current in two distinct phases, which is in agreement with the literature for lock-exchange flows with similar characteristics. Results confirm that in the first stage of current development front velocities are nearly constant. When normalized by a characteristic velocity defined with initial quantities of each experiment, $u_{0}$, values of non-dimensional front velocity fall in the range $u_{f} / u_{0}=0.46 \pm$ 0.02 , confirming previous observations. The transition between slumping and self-similar phases occurs when the reflected bore overtakes the front of the current. This stage was seen to occur in the range $\left(x_{f}-x_{0}\right) / x_{0}=8.4 \pm 1.0$, which is in accordance to what has been previously observed. During the self-similar phase, front position decreases in time and is a function of $t^{0.78}$, approximately, which is higher than $t^{2 / 3}$ described in literature. The run performed with higher bed roughness does not follow the general observations since the transition to the self-similar phase occurs earlier than the remaining runs. The deviation of run R3 from the remaining runs is more evident during the self-similar phase, which shows that the effect induced by bed roughness is more relevant during the second stage of current development. For a proper parametrization of the front position in time, a parameter taking into account the roughness and porosity of the bed material is thus required.
The increase in the initial density of the mixture in the lock has a direct effect on the front propagation, higher front velocities being detected when the initial buoyancy of the gravity current increases. When normalizing the evolution of the front position by the initial parameters $x_{0}$ and $u_{0}$, a good data collapse was obtained. Besides front velocity, the initial density was seen to influence the size and periodicity of the large-scale instabilities present in the mixing layer: evident large-scale billows with regular periodicity were detected in the run performed with the lowest density tested. Increasing the initial density was seen to reduce the number of detected large-scale billows.

Results confirm that bed roughness plays an important role in the current development. The influence of the bed roughness apparently depends on its length scale. Three materials with different $D_{50}$ to reproduce different rough beds were investigated; runs R1 and R2, with lower $D_{50}$, show a smooth deceleration in the front propagation; run R3, in turn, presents a stronger deceleration, as expected, but no significant dilution is observed when compared with the smooth bed case (run D2). These observations show that bed roughness plays an important role in the current kinematics and it needs further investigation.

Large-scale instabilities present in the mixing layer between current and ambient fluid are well observed in the plots of current height. The length scale and the periodicity of these structures seem to depend both on the initial buoyancy of the current and on bed roughness: as the initial buoyancy increases, billows with smaller length scales are observed and no well-defined spatial periodicity is detected; regarding the effect of bed roughness, it was observed that an increase in the size of the bed material induces a homogenizing effect throughout the current height, less large-scale billows being observed. This may be related to extra turbulent production in the lower levels, inducing extra mixing within the current. The genesis of these large-scale instabilities might be related to dynamics at the current head, which in turn is ruled by local buoyancy forces; as current develops and ambient fluid is being entrained into the current, local density decreases and so does local reduced gravity. The resulting buoyancy forces are reduced allowing fluid to expand in the vertical direction, forming billows with higher length scales.

The analysis of the temporal evolution of current depthaveraged density shows a significantly diluted current in the region of analysis, indicating that entrainment and consequently, current dilution, occurs since the early stages of current development. In these experiments, it was confirmed that the head region is where higher density is observed within the gravity current. This observation was used as a criteria to isolate the head region, enabling an analysis based on local variables at the head.

In the early stages of the current development, no apparent head detached from the remaining current is observed. This may be responsible for the scatter observed in the densimetric Froude numbers in the slumping stage when using local variables, justifying the bulk character of the current propagation at this stage. When the reflected bore overtakes the current front, the current is fragmented into a body and a well-defined head, the front velocity 
being in equilibrium with its buoyancy celerity. Froude numbers defined by all local variables show a plateau around $F=1$ in the self-similar stage, indicating the full dependency of the front velocity on the head dynamics.

\section{Acknowledgements}

This research was supported by the Portuguese Foundation for Science and Technology (FCT), through the research project PTDC/ECM/099752/2008, and the research grant SFRH/BD/48705/2008. Acknowledgements are due to Alexandre Sousa for help in data interpretation. The authors would like to thank the reviewers for helping to improve the content of the manuscript.

\section{Notation}

$a, b=$ parameters of the least-square regression $(-)$

$A \quad=$ volume of the experimental tank per unit width $\left(\mathrm{m}^{2}\right)$

$A_{c} \quad=$ volume of the gravity current per unit width of the tank $\left(\mathrm{m}^{2}\right)$

$A_{0} \quad=$ volume of the ambient fluid per unit width of the $\operatorname{tank}\left(\mathrm{m}^{2}\right)$

$d \quad=$ characteristic length scale of the current $(\mathrm{m})$

$D_{50}=$ median grain size of the sediments $(\mathrm{mm})$

$\mathrm{F}=$ densimetric Froude number $(-)$

$\mathrm{F}_{\mathrm{b}}=$ bulk densimetric Froude number $(-)$

$\mathrm{F}_{\text {head }}=$ densimetric Froude number at the head of the density current $(-)$

$g \quad=$ acceleration due to gravity $\left(\mathrm{m} \mathrm{s}^{-2}\right)$

$g_{0}^{\prime} \quad=$ reduced gravity acceleration of the mixture in the lock $\left(\mathrm{m} \mathrm{s}^{-2}\right)$

$g_{\text {head }}^{\prime}=$ reduced gravity acceleration at the head of the density current $\left(\mathrm{m} \mathrm{s}^{-2}\right)$

$h \quad=$ current height $(\mathrm{m})$

$h_{0} \quad=$ initial water depth in the lock (m)

$h_{m}=$ maximum height of the head of the density current (m)

$h_{r} \quad=$ height at the rear of the head of the density current (m)

$\bar{h} \quad=$ bulk height of the current (m)

$H \quad=$ depth of the ambient fluid (m)

$k_{s}=$ bed roughness $(\mathrm{mm})$

$L_{f} \quad=$ length of the head of the density current (m)

$m_{s} \quad=$ mass of salt $(\mathrm{kg})$

$m_{0} \quad=$ mass of ambient fluid $(\mathrm{kg})$

$r^{2}=$ coefficient of determination $(-)$

$\mathrm{R}_{\mathrm{b}} \quad=$ bulk Reynolds number $(-)$

$\mathrm{R}_{0}=$ Reynolds number based on initial quantities (-)

$t \quad=$ time after the gate removal (s)

$t_{f 1}=$ time after gate removal corresponding to the transition between first and second phases (s)

$u_{0} \quad=$ buoyancy velocity $\left(\mathrm{m} \mathrm{s}^{-1}\right)$

$u_{f} \quad=$ front velocity $\left(\mathrm{m} \mathrm{s}^{-1}\right)$

$u_{f 1}=$ constant front velocity during the first phase $\left(\mathrm{m} \mathrm{s}^{-1}\right)$

$\bar{u}_{f} \quad=$ bulk front velocity $\left(\mathrm{m} \mathrm{s}^{-1}\right)$

$w \quad=$ width of the experimental tank $(\mathrm{m})$

$W \quad=$ local vertically-averaged mass of the current $\left(\mathrm{kg} \mathrm{m}^{-1}\right)$

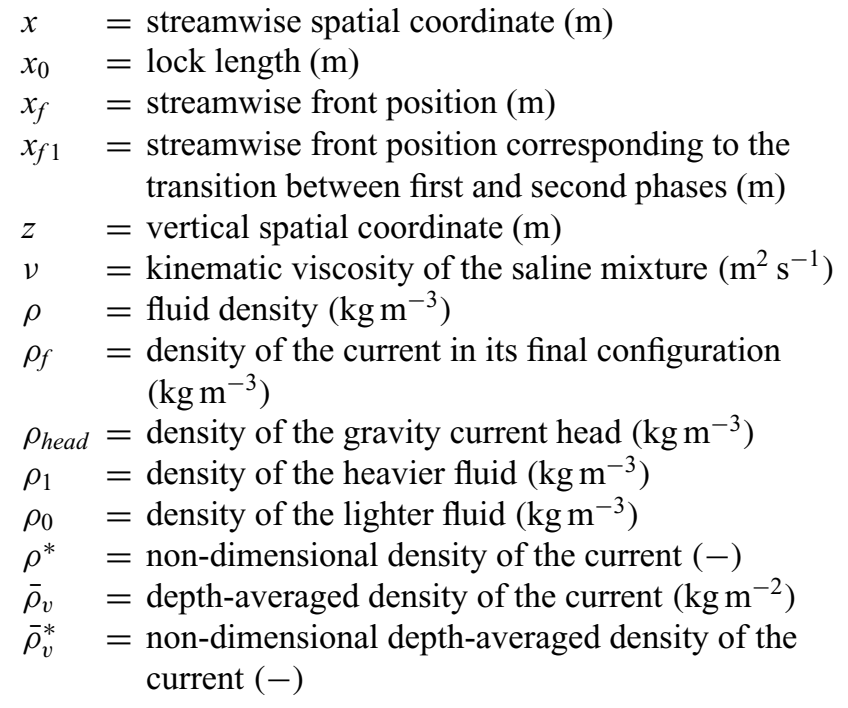

\section{References}

Adduce, C., Lombardi, V., Sciortino, G., Morganti, M. (2009). Roughness effects on gravity currents dynamics. Proc. 33rd IAHR Congress, Vancouver, Canada, 578-585. IAHR (International Association of Hydraulic Engineering \& Research), Madrid.

Adduce, C., Lombardi, V., Sciortino, G., La Rocca, M., Morganti, M. (2011). Analysis of lock release gravity current by PIV. Proc.7th Int. Symp. Stratified flows, Antonio Cenedese, Stefania Espa, Roberto Purini, eds. Università La Sapienza, Rome, Italy, 1097.

Adduce, C., Sciortino, G., Proietti, S. (2012). Gravity currents produced by lock-exchanges: Experiments and simulations with a two layer shallow-water model with entrainment. J. Hydraulic Eng. 138(2), 111-121.

Alahyari, A., Longmire, E.K. (1996). Development and structure of a gravity current head. Exp. Fluids 20, 410-416.

Althaus, J.M.I.J., De Cesare, G., Schleiss, A.J. (2011). Fine sediment release from a reservoir by controlled hydrodynamic mixing. Proc. 34th IAHR World Congress, 662-669, E. Valentine, C. Apelt, J. Ball, H. Chanson, R. Cox, R. Ettema, G. Kuczera, M. Lambert, B. Melville, J. Sargison, eds. Engineers Australia, Brisbane, QLD, Australia.

Altinakar, M.S. (1993). Weakly depositing turbidity currents on small slopes. PhD thesis, École Polytechnique Fédérale de Lausanne (EPFL), Lausanne, Switzerland.

Alves, E., González, J., Freire, P., Cardoso, H. (2008). Experimental study of plunging turbidity currents in reservoirs. Proc. River Flow 2008, 1157-1164, M. Altinakar, M. A. Kokpinar, Y. Darama, B. Yegen, N. Harmancioglu, eds. Kubaba Congress Department and Travel Services, ÇeşmeIzmir, Ankara, Turkey.

Bombardelli, F.A., Cantero, M.I., García, M.H., Buscaglia, G.C. (2009). Numerical aspects of the simulation of descontinuous saline underflows: The lock-exchange problem. J. Hydraulic Res. 47(6), 777-789. 
Cantero, M.I., Lee, J.R., Balachandar, S., García, M.H. (2007). On the front velocity of gravity currents. J. Fluid Mech. 586, $1-39$.

Cenedese, C., Adduce, C. (2008). Mixing in a density driven current flowing down a slope in a rotating fluid. J. Fluid Mech. 604, 369-388.

Cenedese, C., Adduce, C. (2010). A new entrainment parametrization for mixing in overflows. J. Phys. Oceanogr. 40(8), 1835-1850.

Fan, J., Morris, G.L. (1992). Reservoir sedimentation I: Delta and density current deposits. J. Hydraulic Eng. 118(3), 354-369.

Fernandez, R.L., Imberger, J. (2006). Bed roughness induced entrainments in a high Richardson number underflow. J. Hydraulic Res. 44(6), 725-738.

García, C.M., Oberg, K., García, M.H. (2007). ADCP measurements of gravity currents in the Chicago river, Illinois. J. Hydraulic Eng. 133(12), 1356-1366.

Gerber, G., Diedericks, G., Basson, G.R. (2011). Particle image velocimetry measurements and numerical modeling of a saline density current. J. Hydraulic Eng. 137(3), 333-342.

Hacker, J., Linden, P.F., Dalziel, S.B. (1996). Mixing in lockrelease gravity currents. Dyn. Atmos. Ocean 24, 183-195.

Hallworth, M.A., Huppert, H.E., Phillips, J.C., Sparks, R.S.J. (1996). Entrainment into two-dimensional and axisymmetric turbulent gravity currents. J. Fluid Mech. 308, 289-311.

Härtel, C., Meiburg, E., Necker, F. (2000). Analysis and direct numerical simulation of the flow at a gravity-current head. Part 1. Flow topology and front speed for slip and no-slip boundaries. J. Fluid Mech. 418, 189-212.

Huppert, H.E. (1982). The propagation of two-dimensional and axisymmetric viscous gravity current over a rigid horizontal surface. J. Fluid Mech. 121, 43-58.

Huppert, H.E., Simpson, J.E. (1980). The slumping of gravity currents. J. Fluid Mech. 99(4), 785-799.

Kantoush, S.A., Sumi, T., Murasaki, M. (2010). Evaluation of sediment bypass efficiency by flow field and sediment concentration monitoring techniques. J. Hydraulic Eng. 55, 169-173.

Kestin, J., Khalifa, H.E., Correia, R.J. (1981). Tables of the dynamic and kinematic viscosity of aqueous $\mathrm{NaCl}$ solutions in the temperature range $20-150^{\circ} \mathrm{C}$ and the pressure range 0.1-35 MPa. Phys. Chem. Ref. Data 10(1), 71-87.

Khavasi, E., Afshin, H., Firoozabadi, B. (2012). Effect of selected parameters on the depositional behaviour of turbidity currents. J. Hydraulic Res. 50(1), 60-69.

Kostic, S., Parker, G. (2003). Progradational sand-mud deltas in lakes and reservoirs. Part 1 . Theory and numerical modeling. J. Hydraulic Res. 41(2), 127-140.

La Rocca, M., Adduce, C., Sciortino, G., Pinzon, A.B. (2008). Experimental and numerical simulation of three-dimensional gravity currents on smooth and rough bottom. Phys. Fluids 20(10), 106603.

La Rocca, M., Adduce, C., Lombardi, V., Sciortino, G., Hinkelmann, R. (2012a). Development of a lattice Boltzmann method for two-layered shallow-water flow. Int. J. Numer. Meth. Fluids 70(8), 1048-1072.

La Rocca, M., Adduce, C., Sciortino, G., Pinzon, A.B., Boniforti, M.A. (2012b). A two-layer, shallow water model for 3D gravity currents. J. Hydraulic Res. 50(2), 208-217.

Legg, S. (2012). Overflows and convectively driven flows. In Buoyancy-driven Flows, 203-239, E. Chassignet, C. Cenedese, J. Verron, eds. Cambridge University Press, New York.

Marino, B.M., Thomas, L.P., Linden, P.F. (2005). The front condition for gravity currents. J. Fluid Mech. 536, 49-78.

Martin, J.E., García, M.H. (2009). Combined PIV/PLIF measurements of a steady density current front. Exp. Fluids 46, 265-276.

Nogueira, H.I.S., Adduce, C., Alves, E., Franca, M.J. (2012). Visualization and characterization of gravity currents over rough beds by means of PIV measurements. Proc. 2nd IAHR Europe Congress, P. Rutschmann, M. Grünzner, S. Hötzl, eds. Munich.

Nogueira, H.I.S., Adduce, C., Alves, E., Franca, M.J. (2013). Image analysis technique applied to lock-exchange gravity currents. Meas. Sci. Technol. 24(047001), 4pp.

Oehy, C., Schleiss, A.J. (2007). Control of turbidity currents in reservoirs by solid and permeable obstacles. J. Hydraulic Eng. 133(6), 637-648.

Ooi, S.K., Constantinescu, G., Weber, L.J. (2007). 2D Largeeddy simulation of lock exchange gravity current flows at high Grashof numbers. J. Hydraulic Eng. 133(9), 1037-1047.

Özgökmen, T.M., Fischer, P.F. (2008). On the role of bottom roughness in overflows. Ocean Model. 20(9), 336-361.

Paik, J., Eghbalzadeh, A., Sotiropoulos, F. (2009). Treedimensional unsteady RANS modelling of discontinuous gravity currents in rectangular domains. J. Hydraulic Eng. 135(6), 505-521.

Parsons, J.D., García, M.H. (1998). Similarity of gravity current fronts. Phys. Fluids 10(12), 3209-3213.

Peters, W.D., Venart, J.E.S. (2000). Visualization of roughsurface gravity current flows using laser-induced fluorescence. Proc. 9th Int. Symp. Flow Visualization, 244-1-244-11, G.M. Carlomagno, I. Grant, eds. Heriot-Watt University, Edinburgh.

Rossato, R., Alves, E. (2011). Experimental study of turbidity currents flow around obstacles. Proc. 7th Int. Symp. Stratified Flows, A. Cenedese, S. Espa, R. Purini, eds. Università La Sapienza, Rome, Italy.

Rottman, J.W., Simpson, J.E. (1983). Gravity currents produced by instantaneous releases of a heavy fluid in a rectangular channel. J. Fluid Mech. 135, 95-110.

Shin, J.O., Dalziel, B.S., Linden, P.F. (2004). Gravity currents produced by lock exchange. J. Fluid Mech. 521, $1-34$.

Simpson, J.E. (1997). Gravity currents: In the environment and the laboratory. ed. 2. Cambridge University Press, New York. 
Thomas, L.P., Dalziel, S.B., Marino, B.M. (2003). The structure of the head of an inertial gravity current determined by particle-tracking velocimetry. Exp. Fluids 34, 708-716.

Tokyay, T., Mohamed, Y.A., Constantinescu, G. (2011). Effect of Reynolds number on the propagation of the lock exchange gravity currents in a porous medium. Proc. 34th IAHR Congress, 2962-2969, E. Valentine, C. Apelt, J. Ball,
H. Chanson, R. Cox, R. Ettema, G. Kuczera, M. Lambert, B. Melville, J. Sargison, eds. Engineers Australia, Brisbane, QLD, Australia.

Zhu, J.B., Lee, C.B., Chen, G.Q., Lee, J.H.W. (2006). PIV observation of instantaneous velocity structure of lock release gravity currents in the slumping phase. Commun. Nonlinear Sci. Numer. Simul. 11, 262-270. 